\title{
Nonlinear Predictive Control Method for Maximizing Wind Energy Extraction of Variable Speed Wind Turbines under Turbulence
}

\author{
Ahmed Aissaoui, Houari Khouidmi ${ }^{*}$, Ahmed Benzouaoui, Boubaker Bessedik \\ Department of Electronics, Faculty of Technology, Hassiba Benbouali University of Chlef, Chlef 02000, Algeria
}

Corresponding Author Email: h.khouidmi@univ-chlef.dz

https://doi.org/10.18280/jesa.540501

Received: 29 March 2021

Accepted: 15 July 2021

\section{Keywords:}

variable-speed wind turbines, wind energy extraction, nonlinear optimization, predictive control

\begin{abstract}
Generally, wind turbines are controlled by Maximum Power Point Tracking (MPPT) strategies in order to achieve maximum power extraction below its rated value. But it is very difficult to adjust the rotor speed according to the highly fluctuating wind speed accurately and quickly, due to the large inertia of wind turbines, and therefore, the efficiency of wind energy extraction will never reach its theoretical maximum value. To address this problem, a new method has been developed in this paper which is totally different from the known classical methods. In this paper a wind speeds prediction for maximum wind energy extraction (MWEE) of variable-speed wind turbines (VSWTs) is presented. A nonlinear predictive control is developed by solving a nonlinear optimization problem to generate the optimal generator torque sequence and consequently the previewed rotor speeds with maximum wind energy extraction. A detailed explanation has been provided of how this new method works through a detailed block diagram; accurate algorithm and flowchart. The proposed nonlinear predictive method takes full advantage and the MWEE objective is confirmed by the simulation results compared to the classical TSR methods.
\end{abstract}

\section{INTRODUCTION}

In recent years, with the increasing importance of global climate problem and the growing demand for energy as well as pollution from the use of fossil fuels has pushed the general public to use renewable energies. In this context, wind power is one of the important sources of renewable energy that presents an outcome to our energy production problems. Moreover, this energy seems the most promising, nonpolluting and inexhaustible. However, the production of this energy is non-linear and it varies according to the wind speed [1]. Wind energy is one of the fastest growing renewable energy sources in the world. Wind power generation capacity has doubled worldwide, and reaching $650.8 \mathrm{GW}$ by the end of 2020 [1-3]. Hence, research and development on wind energy are of great practical value at present.

Because wind turbines are large and flexible structures that operate in noisy environments, they represent a myriad of control issues that, if resolved, can reduce the cost of wind energy [4]. In the field of wind power generation technology, the variable speed wind power generation system (VSWT) has many advantages over the advantages of fixed speed such as better power quality, higher overall efficiency, lower mechanical stress and increased power [5]. Therefore, it can be controlled to enable the turbine to operate at maximum power factor and to ensure the Maximum Power Tracking Capacity (MPTC) [6]. For VSWT based generator control, full power electronic inverter systems are generally used as an interface between the VSWT and the electrical grid to meet new standards and network connection requirements [7, 8]. Thus, it allows controlling the wind turbine system, separating the generator from the power grid, and the VSWT does not need to synchronize its rotational speed with the frequency of the electrical grid [9]. Thus, VSWT is able to achieve high efficiency and performance when connected to electrical network, not only under normal working conditions but also under irregular and faulty network conditions [10, 11]. Standard control laws [5] require the complex aerodynamic properties to be well known so that variable speed turbines can maximize energy capture; In practice, uncertainties limit the energy capture efficiency of variable speed wind turbines.

\subsection{Literature review}

The variable speed operation makes it possible to adjust the rotational speed of the wind turbine continuously and in accordance with the wind speed. This method makes the turbine operate at its highest stage of aerodynamic efficiency $[5,7]$. The goal of controlling the rotational speed is always to generate the maximum power and there are two types of strategies for controlling the rotational speed [7, 12-15]. The first is the speed control case, which depends on the acquisition of a reference rotational speed leading to an ideal maximum speed and therefore requires a speed control loop. This method ensures a fast achievement of maximum power by using a speed control loop with a wide bandwidth, but the output power quality is not very good $[12,13]$. The second is the torque control case, where in this case the controller must also adjust the torque of the reference generator so that the resulting power is maximum $[14,15]$. A maximum power reference electromagnetic torque is given to the internal torque control loop. With a sudden increase in wind speed, there will be an increase in the torque of the turbine and since the speed of the turbine cannot increase directly, the torque remains the 
same, producing an accelerating torque until the new ideal point of operation is achieved [15]. In comparison between the two strategies, the results show that the speed control case follows the wind speed more accurately in order to achieve a higher power factor more accurately, that is, it is more suitable for the rapid achievement of the maximum power. More power because speed is forcibly applied to the turbine so from a quality point of view the torque strategy represents better performance. This is because the speed is not applied directly to the turbine, and this control enables the wind turbine to freely change the rotational speed during operation.

At present, the research related to maximum power extraction control for a variable speed wind turbine mainly covers two main categories: linear control and nonlinear control [16]. Research in linear controller mainly contains PID controller [17-19], robust controller based on the linear matrix inequality approach $L M I[20,21]$, and linear quadratic control $L Q R$ [21]. The nonlinear control component mainly contains in many studies predictive control methods $P C$ [22-29] and some intelligent control methods such as neural, fuzzy and sliding mode control [17, 30-35]. Because a wind turbine is a multi-input, multi-output system that has strongly nonlinear dynamics, the effect of nonlinear control is better than linear control [36]. Taking into account the complexity of the algorithm, most of the recently introduced controllers are nonlinear. Therefore, a variable speed wind turbine design with a nonlinear predictive controller $P C$ taking into account the nonlinear characteristics of a wind turbine has become the key. Therefore, this article takes this type of control as the focus of the study and summarizes some valuable conclusions.

The technique of maximum power point tracking (MPPT) is usually used in variable speed wind power systems to extract maximum power. Therefore, several works have focused on wind power systems. They tried to develop algorithms to extract the maximum of energy converted by the turbine and thus allow optimal operation of the wind system [37, 38]. Authors in $[12-15,32,39]$ presented a MPPT methods requiring prior knowledge of the characteristic of the turbine (methods based on wind speed measurement models (WSR)). The MPPT algorithms through Speed control [12, 39], Torque control $[14,15]$, Direct and Indirect power control $[8,28]$, are some more relevant approaches used in the recent works in this area. Further, the other controls of the variable speed wind turbine (VSWT) system include the maximum energy extraction control and the pitch angle control [17, 40-42] are well cited and referred in the literature. These type of control methods are mainly on the TSR [32] and Power signal feedback $(P S F)$ [13], it characterized by its efficiency, its rapidity in following the maximum point despite the variation of the wind speed, except that its efficiency tends to reduce with the aging of the wind turbine and the change of the turbine characteristic. References [30-35, 43, 44] present an efficient $M P P T$ methods which does not require any knowledge of the turbine characteristics (methods without wind speed measurement models). These type of control methods are mainly on the Optimal Torque Control (OTC) [14, 15], Perturb and Observe $(P \& O)$ [43-45], Hill-Climbing Search (HCS) [46], Backstepping Control (BSC) [47], Sliding Mode control (SM) $[33,34]$ and various recent artificial intelligence techniques like Fuzzy Logic $(F L C)$ [20, 21], Artificial Neural Network method (ANN) [30], Particle Swarm Optimization (PSO) [48], it manages to reach the maximum energy extraction except that its rapidity is reduced especially in the presence of variation in wind speed.
The discrete time controller designed by Yazici and Yaylaci [35] to bring the system to a reference point by implementing the MPPT algorithm, showed better performance in terms of time ripple stability, however this algorithm did not work under sudden changes in wind speed. Since the conventional $O T$ response has a slow response due to high inertia, the authors [14] developed an optimal torque control (OTC) where an effective tracking range was proposed to obtain stable $M P P$ efficiency. It was confirmed that the indirect method works best for $M P P$ compared to the direct methods in the work presented by Liu et al. [49] for a small-scale WECS system with a pilot analysis of energy efficiency due to the effect of $M P P T$. Due to the simplicity and flexibility of the HCS-based algorithms that have been recently covered in many works [39, $46,50,51]$, it remains difficult to control turbulence direction, step size, and the ability to track changes in maximum power at low speeds [12]. These are problems that were overcome [44] by implementing $H C S$ algorithms and adaptive steptracing for $M P P$. It is also replaced by an additional conductivity algorithm (INC) $[49,52]$ in order to improve convergence speed as well as the accuracy and performance of the system. In many works, the $O R B$ algorithms have been touched, especially hybrids, in which the advantages of two models are combined to form a new hybrid model to improve performance [19, 33]. These algorithms require knowledge of the system parameter and also the optimal curve that is complex to obtain in real-time applications $[49,53]$ which has been overcome in the existing adaptive MPPT [42] which has all the advantages, especially the ability to track the $M P P$ during dynamic wind speed changes, and the $M V P O$ algorithm [42] can also be used to maximize power generation as it does not require any sensors and control circuits to be implemented. Recently, applications of soft computing techniques such as $N N s$ and fuzzy logic of MPP have been successfully implemented in the references $[49,52]$. Features of fuzzy and $N N$ controls are that the control algorithms are universal and give fast and insensitive case projection it accepts noise signals and imprecise signals. These methods are not limited, but there are also several control strategies of MPPT $[9,54]$ algorithm proposed to overcome its shortcomings.

Usually, the maximum wind power extraction (MWEE) achieved through the maximum power point tracking MPPT is insufficient, due to the increased inertia of the rotor and the high turbulent winds $[6,37,38]$ which impede the achievement of the maximum power point tracking in variable speed wind turbines. To improve the wind energy extraction for Variable Speed Wind Turbines (VSWTS), numerous and advanced predictive methods employing previewed wind speeds have been developed such as the work proposed by Song et al. [22-24], Kitajima et al. [25] and Roig [26]. Unlike the existing methods for MWEE [25-29] that use linear prediction models and the quadratic programming algorithm to calculate the optimal solution of the given cost functions. The quadratic programming algorithm is computationally complex and requires large computational resources which make it difficult to be implemented in real time applications.

Comparing to the numerous researches on MPPT strategies of $V S W T$, the MPP technique based nonlinear predictive method has received less attention due to its heavy computational burden. However, it has been shown in some new studies [22-24] that NPC methods combined with nonlinear optimization and an algorithm to search the optimal generator torque can improve the control performance of $W T$, 
especially to obtain the maximum power extracted from the VSWT with less computational burden.

This paper presents a novel nonlinear predictive control based on a nonlinear optimization problem and an efficient search method based on a neighboring search technique to search the optimal generator torque sequence.

\subsection{Background and motivation of the study}

As shown in Figure 1, if the wind speed is $V_{v(1)}$ and the turbine is operating at point $A$ of the turbine speed $\Omega_{t}(1)$. It can increase the output power to the maximum value at point B by increasing the turbine speed to $\Omega_{t}(2)$. Suppose the wind speed now changes to $\mathrm{V}_{v(2)}$, the output power changes to point $\mathrm{C}$, at this wind speed the maximum energy can be extracted by increasing the turbine speed to $\Omega_{t}(3)$ and so forth. Without a doubt, when the wind speed changes, the turbine speed must follow these changes, in order to extract the maximum power.

Recently, the work presented by Song et al. [22] is the only work that deals with this type of nonlinear predictive method for $M W E E$ of $V S W T$, where the authors presented the basics and principles of this novel method for 1.5 and $5 \mathrm{MW} W T$. Although, this method uses a cost function with one variable (energy variable only) to select the optimal generator torque and consequently to confirm the maximum wind energy extraction. A cost function with one variable is not reasonable and exhaustive; and the predicted turbine (rotor) speed is not considered in the cost function, this consideration does not necessarily give the optimal solution for certain predicted turbine speeds.

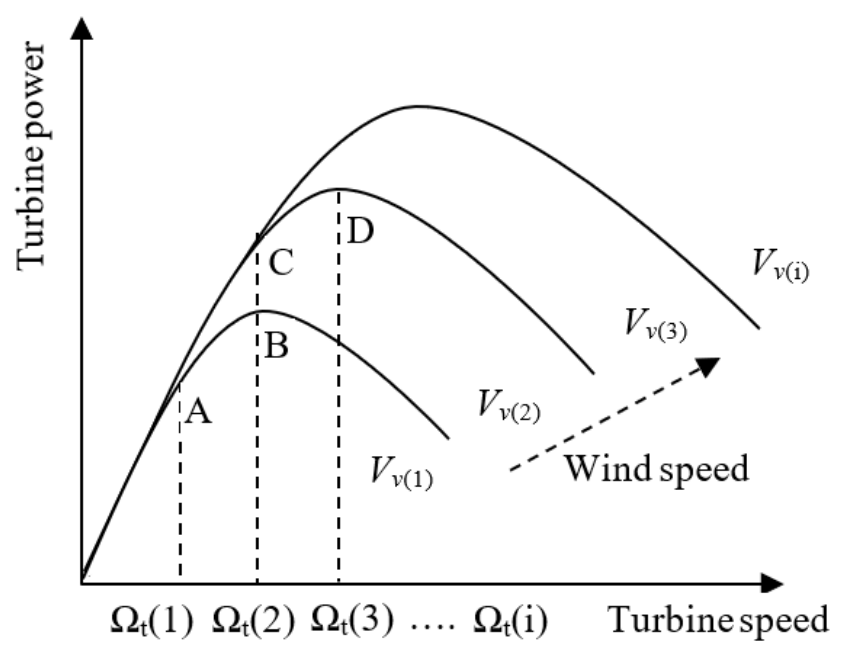

Figure 1. Turbine power versus speed at different wind speed

The main objectives of this study are theoretical evaluation, design, simulation validation and comparison of the proposed nonlinear predictive control method with conventional TSR based MPPT technique for $1.5 \mathrm{MW} W T$. The proposed method has been tested on a simple wind turbine model by using the $M A T L A B$ software. It should be noted here that the work presented by Song et al. [22] was also done by the NREL offshore 1.5 and $5 \mathrm{MW}$ wind turbine model using the FAST aeroelastic simulator, and used the wind data generated by TurbSim simulator.

The rest of the paper is organized as follows: First the $W T$ 's and generator speed control based TSR technique are presented in Section II. Section III presents the problem statement of the proposed NPC method for MWEE of VSWT's. The NPC control design and implementation are presented in Section IV. The simulation results of the proposed approach for $M W E E$ of $V S W T$ 's are presented in Section V. Finally, the conclusions of the paper are summarized in Section VI.

\section{WIND ENERGY CONVERSION MODELING AND CONTROL}

A wind turbine extracts kinetic energy from the swept area of the blades, as shown in Figure 2, a variable speed wind turbine mainly consists of a wind turbine, gearbox, and generator. It is also known that the energy taken from the wind turbine is dependent to three parameters: availability of wind energy, power curve of the turbine, and the ability of this turbine to respond to wind fluctuations.

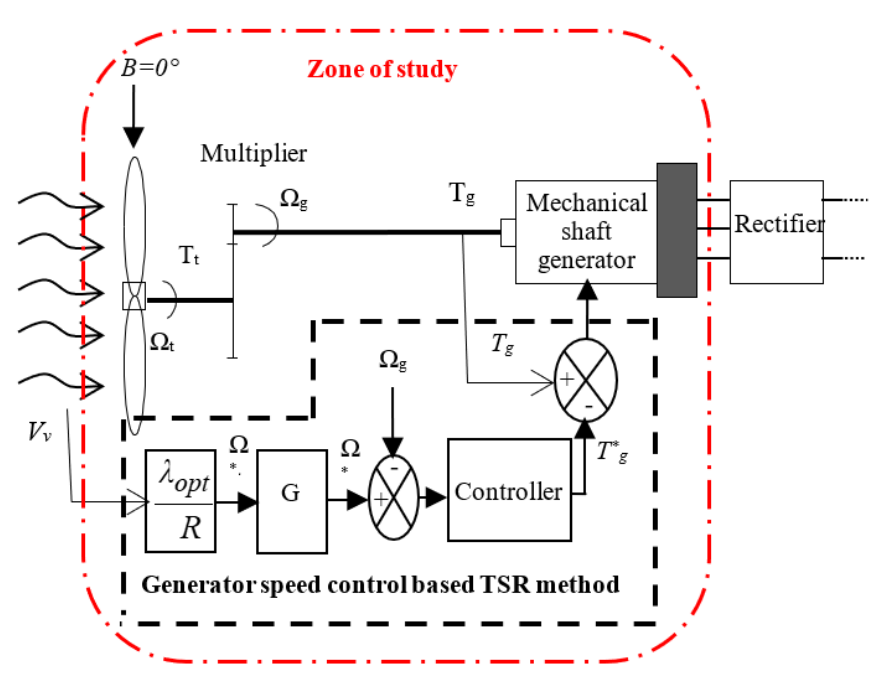

Figure 2. Block diagram of controlled wind energy conversion system

The aerodynamic energy extracted from the wind turbine is expressed through the following nonlinear relationship:

$$
P_{\text {aer }}=\Omega_{t} T_{t}=\frac{1}{2} \rho \pi R^{2} C_{p}(\lambda, \beta) V_{v}^{3}
$$

where:

$$
\lambda=\frac{R \cdot \Omega_{t}}{V_{v}}
$$

$\lambda$ is called the vertical speed ratio (Tip Speed Ratio TSR), and it is the ratio between the linear speed of the vertical blade and the wind speed $V_{v}(\mathrm{~m} / \mathrm{s})$. While $R$ is the rotor radius $(\mathrm{m}), \beta$ is the blades wedge angle, $\rho$ is air density $\left(\mathrm{kg} / \mathrm{m}^{3}\right), \Omega_{t}$ is the turbine speed $(\mathrm{rad} / \mathrm{s}), T_{t}$ is the turbine torque $(\mathrm{Nm})$ and $C_{P}$ is the power coefficient.

Thus, any change in the speed of the rotor or the wind speed is associated with a change in the ratio of the vertical speed, and this leads to the difference in the power coefficient $C_{p}$, and thus leads to a change in the extracted energy.

The power coefficient is given by a non-linear function approximation of the relative speed $\lambda$ and the blades wedging $\beta$ [28]. 


$$
\begin{gathered}
C_{p}(\lambda, \beta)=(0,5-0,00167(\beta-2)) \\
\sin \left[\frac{\pi(\lambda+0,1)}{10-0,3(\beta-2)}\right]- \\
0,00184(\lambda-3)(\beta-2))
\end{gathered}
$$

In the framework of average wind speed, the maximum value of the wind speed must be extracted, and the blades wedging $\beta$ must be fixed to the optimum value of the angle in order to keep the value of $\lambda$ at its optimum value $\left(\lambda_{o p t}\right)$, and the rotor speed to track the reference, which has the same shape as the wind speed and proportional to it by the gearbox ratio $G$ (multiplier model). Therefore, the generator torque and rotor (turbine) speed are given by:

$$
\begin{gathered}
T_{g}=\frac{T_{t}}{G} \\
\Omega_{t}=\frac{\Omega_{g}}{G}
\end{gathered}
$$

The fundamental equation of the dynamics of the mechanical shaft generator is given by the following simple two-mass model:

$$
\left(\frac{J_{t}}{G}+G J_{g}\right) \frac{d \Omega_{t}}{d t}=T_{t}-G T_{g}-K_{f} G . \Omega_{t}
$$

where, $J_{t}$ and $J_{g}$ are the rotor and generator inertia, respectively, and $K_{f}$ is viscous friction coefficient.

When the wind turbine captures the maximum wind power, there is a value of $T S R \approx \lambda_{\text {opt }}$ for which power coefficient is maximized $C_{p}=C_{p}^{\max }$. So there exists a specific point in the wind generator power characteristic, called maximum power point $(M P P)[22,28]$, where the output power is maximized (see Figure 3)

For a variable wind speed $V W S$, the referential generator and rotor speed are given by:

$$
\begin{gathered}
\Omega_{t}^{*}=\frac{\lambda_{\text {opt }} V_{v}}{R} \\
\Omega_{t}^{*}=\frac{\Omega_{g}^{*}}{G}
\end{gathered}
$$

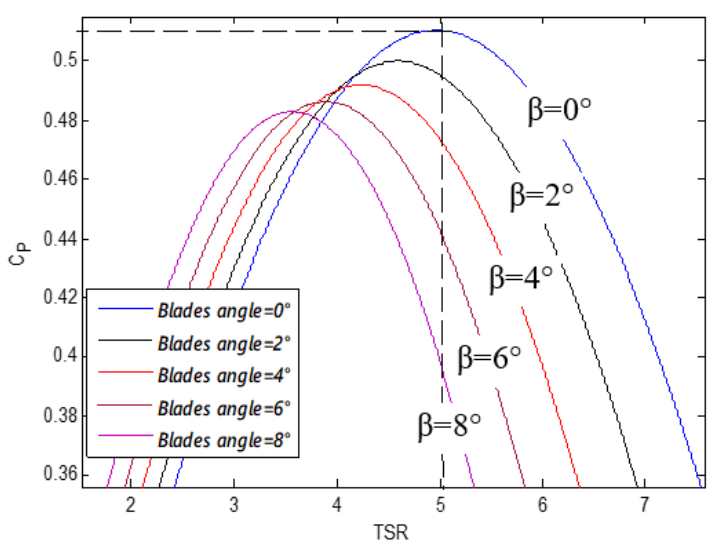

Figure 3. Power coefficient versus TSR at different blades pitch angle

\section{PROBLEM STATEMENT}

\subsection{Wind energy extraction}

In $V S W T S, V_{v}$ is turbulent and $W T s$ have a large inertia so it is impractical to maintain the maximal power coefficient $C_{p}^{\max }$ during the long evaluation period $T$. Hence the extracted wind energy $E$ during a certain short evaluation periods $n$ can be expressed as:

$$
\begin{gathered}
E=\sum_{i=1}^{n} P_{a e r(i)} \Delta k=\sum_{i=1}^{n} K V_{v(i)}^{3} C_{p(i)}\left(\lambda_{(i)}, \beta\right) \Delta k \\
=K \Delta k\left(\begin{array}{c}
V_{v(1)}^{3} C_{p(1)}\left(\lambda_{(1)}, \beta\right)+ \\
+V_{v(2)}^{3} C_{p(2)}\left(\lambda_{(2)}, \beta\right)+\ldots \\
\ldots . .+V_{v(n)}^{3} C_{p(n)}\left(\lambda_{(n)}, \beta\right)
\end{array}\right)
\end{gathered}
$$

where, $K=\rho \pi R^{2} / 2$ and $\Delta k$ is the time length of the short evaluation period, $V_{v(1)} V_{v(2)}, \ldots V_{v(n)}$ and $C_{p(1)}, C_{p(2)}, \ldots . C_{p(n)}$ are averaged values of wind speed and power coefficient in the $n$ short periods, respectively.

\subsection{Rotor speed prediction}

Based on the rotor speed Eq. (1) and rotor speed derivative (6), all possible future rotor speeds values can be predicted using the following Euler forward formula:

$$
\frac{d X}{d t}=\frac{X(k+1)-X(k)}{\Delta k}
$$

where, $\Delta k$ evaluation period

According to Eqns. (1) and (6), the averaged rotor speeds $\Omega_{t}(i=1,2, \ldots \ldots, n)$ in short evaluation period $\Delta k$ re predicted using Euler formula (10), by:

$$
\begin{aligned}
\Omega_{t}(i+1) & =\frac{K V_{v(i)}^{3} C_{p(i)}\left(\lambda_{(i)}, \beta\right)}{J_{R} \Omega_{t}(i)} \Delta k \\
& -\frac{G}{J_{R}} T_{g(i)} \Delta k+\left(1-\frac{K_{f} G}{J_{R}} \Delta k\right) \Omega_{t}(i)
\end{aligned}
$$

where, $T_{g(i)}$ is the generator torque at the $i^{\text {th }}$ control period. With:

$$
\begin{gathered}
\Omega_{t}(i)=\frac{V_{v(i)} \lambda(i)}{R} \\
J_{R}=\left(\frac{J_{t}}{G}+G J_{g}\right)
\end{gathered}
$$

\subsection{Neighboring torque search technique}

The dynamics of the electrical generator is expressed by (14) $[22,24]:$

$$
\dot{T}_{g}=\frac{T_{g(i+1)}-T_{g(i)}}{\Delta k} \cong \frac{T_{g}^{*}-T_{g(i)}}{\tau_{g}}
$$


where, $\tau_{g}$ is the time constant of the electrical system, and $T_{g}^{*}$ is demanded generator torque.

Provided that $\tau_{g} \ll \Delta k$, the generator dynamics can be ignored in the control period of $\Delta k$ and thus in (14), the optimal generator torque $T_{g(i=1)}$ is equal to the demanded $T_{g}^{*}$, and constrained by $[22,24]$ :

$$
T_{g(i)} \in\left\lfloor T_{g}^{\min }, T_{g}^{\max }\right\rfloor
$$

where, $T_{g}^{\min }$ and $T_{g}^{\max }$ are the lower and upper boundaries, respectively; and their values are dynamically adjusted by (16) and (17).

$$
\begin{aligned}
T_{g}^{\min } & =k^{o p t}\left[\min \left(\Omega_{t}, \Omega_{t}^{\min }(i)\right) \sigma_{1}\right]^{2} \\
T_{g}^{\max } & =k^{o p t}\left[\max \left(\Omega_{t}, \Omega_{t}^{\max }(i)\right) \sigma_{2}\right]^{2}
\end{aligned}
$$

where: $k^{o p t}$ is the optimal gain, $\Omega_{t}^{\min } \Omega_{t}^{\max }$ are minimal and maximal turbine speed; $\sigma_{1}$ and $\sigma_{2}$ are two constants, which are smaller and bigger than 1, respectively. However, these coefficients are usually determined empirically by trial and error.

With:

$$
\begin{gathered}
k^{o p t}=\frac{\rho \cdot \pi R^{5} C_{p}^{\operatorname{mxx}}}{2 \cdot G \lambda_{o p t}^{3}} \\
\Omega_{t}^{\min }(i=1,2, \ldots ., n)= \\
\min \left\{V_{v(1)}, V_{v(2)}, \ldots ., V_{v(n)}\right\} \lambda_{o p t} / R \\
\Omega_{t}^{\max }(i=1,2, \ldots . ., n)= \\
\left.\max _{\left(i, V_{v(1)}, V_{v(2)}, \ldots . ., V_{v(n)}\right\}}\right\} \lambda_{o p t} / R
\end{gathered}
$$

After dividing the allowable range in (15) into $h$ subsections, a finite control set is used containing the elements $h$ of the candidate $T_{g(i)}$ which is expressed as follows:

$$
T_{g(i)} \in\left\lfloor T_{g}^{\min }, T_{g}^{\min }+\Delta T_{g}, \ldots . ., T_{g}^{\max }\right\rfloor
$$

With:

$$
\Delta T_{g}=\left(T_{g}^{\max }-T_{g}^{\min }\right) / h
$$

To reduce the calculation burden, we applied a neighboring search technique to the remaining $n-1$ evaluation periods, while the full-range search was performed for the first evaluation period.

The candidate of $T_{g(i+1)}$ is given by:

$$
T_{g(i+1)} \in\left\lfloor T_{g}^{\min }, T_{g}^{\min }+i \Delta T_{g}\right\rfloor
$$

where, $i=0,1, \ldots, n_{b}-1$ and $n_{b}<n$ is the number of the neighbors.

The neighboring search technique reduce the computation burden from $n^{i}$ to $n^{*} n_{b}{ }^{i-1}\left(n_{b}<n\right)$. Thus, the computation burden is determined by the selection of $i, n$ and $n_{b}$.

The value of $n_{b}$ must be chosen very carefully, it depends on the variation degree of the wind speed prediction i.e. when the variation degree is large, the value of $n_{b}$ is also large and this results an increase in the computation burden. Therefore, when selecting $n_{b}$, the balance between control performance and computation burden must be taken into account.

\subsection{MWEE optimization problem formulation}

The output power of a wind turbine at various wind speeds is conventionally described by its power curve (Figure 1). It is shown that the mechanical power converted from the turbine blade is a function of the rotational rotor speed, and the converted power is maximized at a particular previewed rotor speed for various wind speed. However, Song et al. [22] proposed the following nonlinear optimization problem for MWEE:

$$
\max _{v(i)}\left[\frac{E}{E_{\max }}\right]=\max _{v(i)}\left[\frac{\sum_{i=1}^{n} V_{v(i)}^{3} C_{p(i)}\left(\lambda_{(i)}, \beta\right)}{\sum_{i=1}^{n} V_{v(i)}^{3} C_{p}^{\max }}\right]
$$

Therefore, the new proposed version of nonlinear predictive control method uses a cost function with two variables instead of one variable in consideration; energy variable and the predicted turbine speed variable to select the previewed wind speed that gives the optimal generator torque and consequently to confirm the maximum wind energy extraction.

$$
\begin{aligned}
& \max _{\Omega_{t}}\left[\frac{E}{E_{\max }}+K_{\omega} \frac{\Omega_{t}}{\Omega_{t}^{n o m}}\right]= \\
& \max _{\Omega_{t}(i+1) \leq \Omega_{t}^{\text {nom }}}\left[\frac{\sum_{i=1}^{n} V_{v(i)}^{3} C_{p(i)}\left(\lambda_{(i)}, \beta\right)}{\sum_{i=1}^{n} V_{v(i)}^{3} C_{p}^{\max }}+K_{\Omega} \frac{\Omega_{t}(i+1)}{\Omega_{t}^{\text {nom }}}\right]
\end{aligned}
$$

where, $E_{\text {max }}$ is the maximum extracted wind energy, $\Omega_{t}^{n o m}$ is the nominal rotor speed and $K_{\Omega}$ is the weighting factor and can neither be too big nor too small.

\section{THE NPC IMPLEMENTATION}

The block diagram representation of the nonlinear predictive control $(N P C)$ method for maximum wind energy extraction of a variable speed wind turbine is shown in Figure 4. The main objective of the $N P C$ control here is to generate the optimal generator torque control signals that preview the rotor speeds according to its current reference with maximum of energy. Based on the prediction model (11), all possible future rotor speeds values can be predicted. Among the group of the predicted rotor speeds values, the one which maximizes the cost function in (25) is selected, and the corresponding set of control signals is the optimal set.

According to the philosophy of $M P C$, only the first generator torque control signal in the optimal set is applied to predict the rotor speed and consequently extract a maximum of power. The other elements of the optimal set are discarded and the process is repeated in each control period with the new 
values in receding horizon technique.

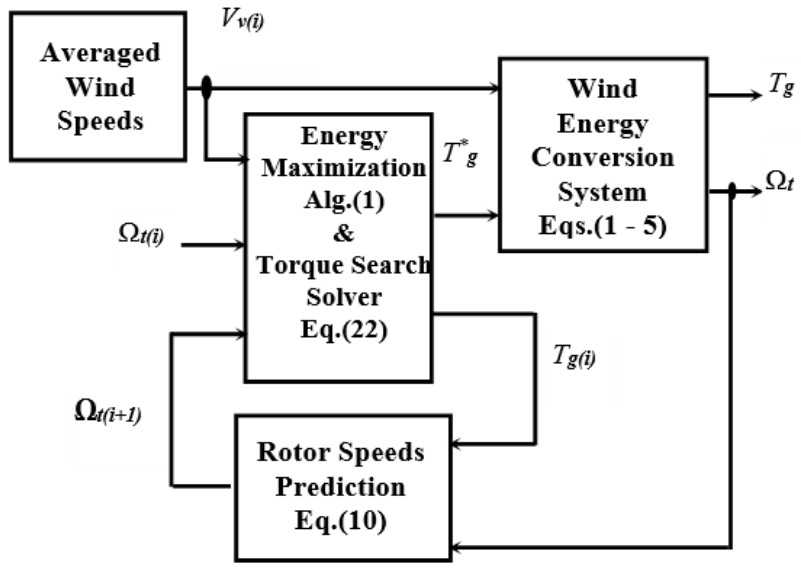

Figure 4. NPC Control scheme for MWEE of VSWT

In the proposed method an iterative algorithm is used, the implementation is detailed in flowchart of Figure 5; it includes six basic steps as shown in Algorithm 1.

Algorithm 1. Implementation of the NPC algorithm for MWEE of VSWT

Step 0: Parameters initialization: $\Delta k, n b, \sigma 1, \sigma 2, K_{\Omega}$

Step 1: Obtain the previewed averaged wind speeds $V_{v(i)}$

Step 2: Define the candidate sets torque sequence $T_{g(i+I)}$, Eq. (22)

Step 3: Predict the rotor speed sequence $\Omega_{t(i+1) \text {, }}$ Eq. (11)

Step 4: Solve (25) for MWEE

Step 5: Save $T_{g}{ }^{*}$ that gives a maximum value of (25); Step 6: Go to step 2 for next control period

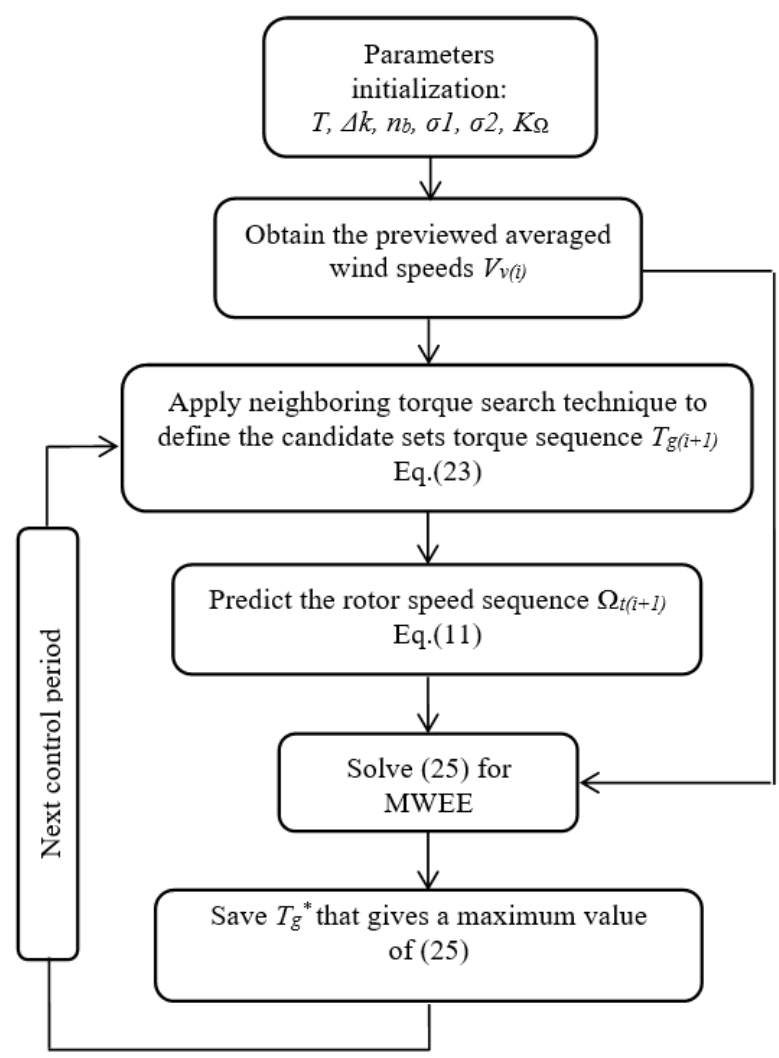

Figure 5. Flowchart of the proposed NPC method for MWEE

\section{SIMULATION RESULTS}

The performances of the proposed NPC scheme of Figure 4 have been tested and verified using Simulink Matlab for a 1.5 MW wind turbine shown in Table 1 . The pitch angle $\beta$ is fixed at $0^{\circ}$ for maximum power coefficient. The applied wind profiles are shown in Figure 6, this wind speed varies between $8 \mathrm{~m} / \mathrm{s}$ and $14.5 \mathrm{~m} / \mathrm{s}$ with mean speed of $10.94 \mathrm{~m} / \mathrm{s}$.

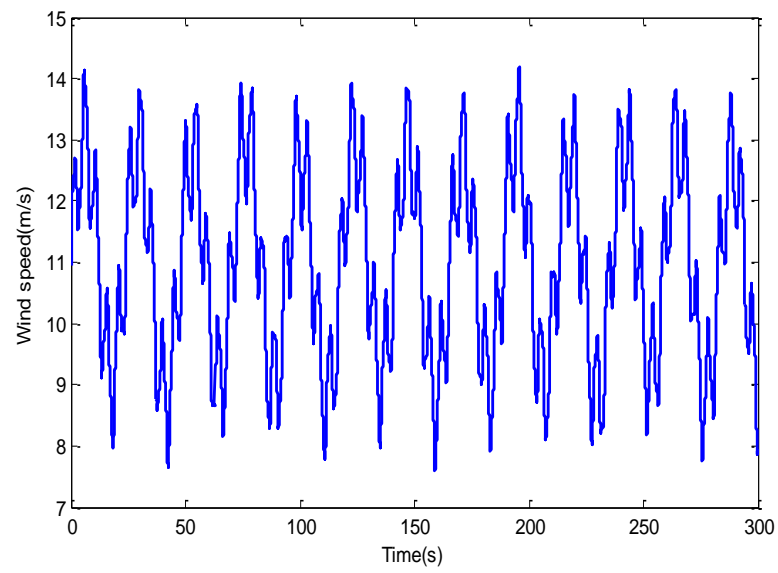

Figure 6. Wind speed profiles

Figure 7 shows the simulation results of the proposed $N P C$ control of VSWT under different wind profiles. In Figure 7.a the rotor speed change from $13 \mathrm{rad} / \mathrm{s}$ to $23.5 \mathrm{rad} / \mathrm{s}$, this variation is a result of the wind speed variation.

To extract maximum wind energy at VSWT, the turbine should necessarily operate at optimal $T S R \approx 4.975$ (Figure 7.b) where the power coefficient $C_{p} \approx 0.510$ (Figure 7.c) which confirm the Eq. (3) for $\beta=0^{\circ}$, this occurs by certain to another predicted wind turbine speed with selected optimal generator torque $T_{g}^{*}$ (Figure $7 . \mathrm{d}$ ). The $N P C$ controller with the setting parameters shown in Table 2 is used to search the optimal generator torque which tracks the maximum extracted power; this principal objective is confirmed when compared the results of the standard TSR controller and the proposed one. As a comparison between the results of the two methods, and as shown in Figure 7.a and 7.b, with the NPC controller the generator speed tracks the wind speed more accurately than that obtained with the TSR controller, and this is due to the optimal generator torque obtained by an efficient and accurate search algorithm. In Figure 7.c, the NPC controller maintains the TSR at the optimal value (4.975) with more precision. Therefore, in Figure 7.d, the power coefficient $C_{p}$ is kept close to the maximal value $(0.510)$ by the $N P C$ controller compared to the TSR controller; As shown in Figure 7.e, over time, the $N P C$ controller extracts more energy than the TSR controller.

Table 1. Wind system parameters [28]

\begin{tabular}{ccc}
\hline Parameter & Value & Unit \\
\hline Rated power & 1500 & $\mathrm{~kW}$ \\
Rated generator speed $\Omega_{\mathrm{g}}$ & 1485 & $\mathrm{Rpm}$ \\
Rotor diameter R & 30 & $\mathrm{M}$ \\
Rotor moment of inertia $\mathrm{J}_{\mathrm{t}}$ & $494 \times 10^{4}$ & $\mathrm{Kgm}^{2}$ \\
Generator moment of inertia $\mathrm{J}_{\mathrm{g}}$ & 21.9388 & $\mathrm{Kgm}^{2}$ \\
Pole pairs & 2 & -- \\
Viscous friction & $673 \times 10^{-3}$ & $\mathrm{~N} . \mathrm{ms}^{-1}$ \\
Maximal power coefficient $C_{p}^{\max }$ & 0.510 & -- \\
Optimal TSR $\lambda_{\text {opt }}$ & 4.975 & -- \\
Gearbox ratio G & 6.8 & -- \\
\hline
\end{tabular}


Table 2. NPC controller parameters

\begin{tabular}{cccccc}
\hline$T$ & $\Delta k$ & $n_{b}$ & $\sigma_{1}$ & $\sigma_{2}$ & $K_{\Omega}$ \\
\hline $10 s$ & $1 s$ & 5 & 1.15 & 1.20 & 0.01 \\
\hline
\end{tabular}
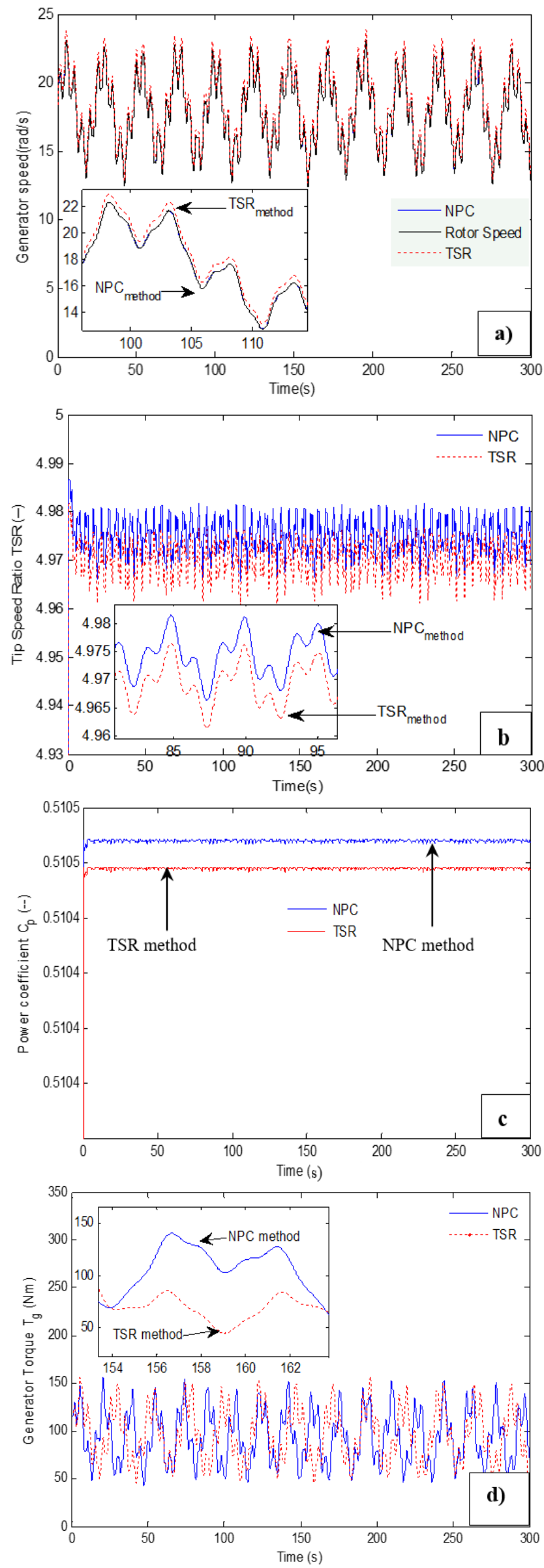

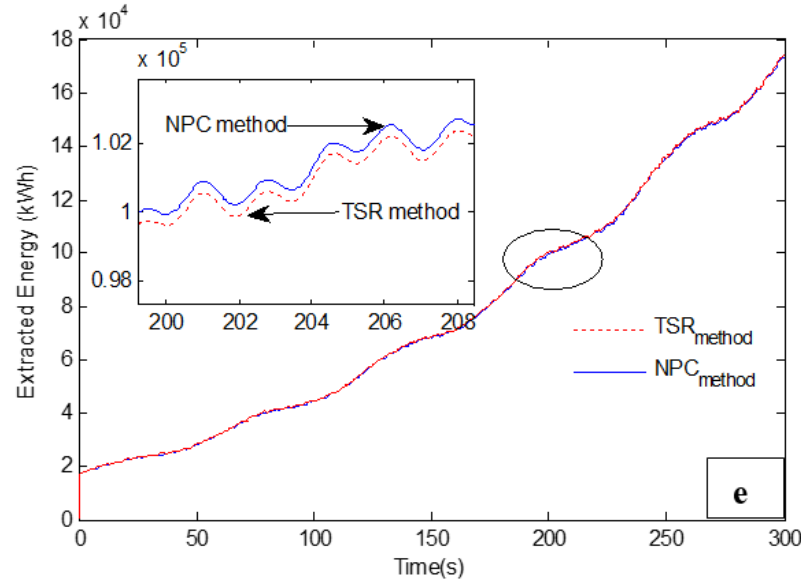

Figure 7. Simulation results of the $N P C$ and TSR control method for MWEE of VSWT: (a) generator speed; (b) TSR; (c) power coefficient; (d) generator torque; (e) extracted energy

The relevant statistical information about mean and standard deviation $S T D$ values of the extracted figures are summarized in Table 3 . In terms of power coefficient and generator torque mean value, it shows that the mean value of $N P C$ method is more than $0.02 \%$ and $1.06 \%$ as the value of TSR method, namely, 0.5105 and $105.78 \mathrm{Nm}$ for $N P C$ versus 0.5104 and $104.67 \mathrm{Nm}$ for TSR. With regard to the power coefficient and generator torque standard deviation $S T D$ values, the $N P C$ and TSR methods have very close $S T D$ values with 0.00012 and $41.65 \mathrm{Nm}$ versus 0.00032 and $42.32 \mathrm{Nm}$ for power coefficient and generator torque, respectively.

This means a decrease in the standard deviation STD of about $62.5 \%$ for the power coefficient and about $1.59 \%$ for the generator torque. Consequently, the efficiency of wind energy extraction by the proposed method is increased by about $3.55 \%$ more than the TSR control method. (Table 4). These good results represented by the decrease in the generator torque indicators and the increase in the power coefficient are only a reflection of the change that we have made in the formulation of the $M W E E$ maximization problem. It should be noted here that the study presented in [22] found that for the generator torque, the standard deviation $S T D$ and the mean value increased by about $66.92 \%$ and $0.07 \%$, respectively, which resulted in a slight increase in the extracted power of the $N P C$ control method that does not exceed $1.87 \%$.

Table 3. TSR and NPC performances evaluation

\begin{tabular}{cccccc}
\hline & Mean $C_{p}$ & Mean $T_{g}$ & $S T D C_{p}$ & $S T D T_{g}$ & $E$ \\
\hline$T S R$ & 0.5104 & $104.67 \mathrm{Nm}$ & 0.00032 & $42.32 \mathrm{Nm}$ & $169 \mathrm{kWh}$ \\
$N P C$ & 0.5105 & $105.78 \mathrm{Nm}$ & 0.00012 & $41.65 \mathrm{Nm}$ & $175 \mathrm{kWh}$ \\
\hline
\end{tabular}

Table 4. Comparison among TSR and NPC in efficiency with Ref. [22]

\begin{tabular}{cccccc}
\hline & Mean & Mean & STD & STD & \multirow{2}{*}{$E$} \\
& $C_{p}$ & $T_{g}$ & $C_{p}$ & $T_{g}$ & \\
\hline NPC/TSR\% & 100.02 & 101.06 & 37.5 & 98.41 & 103.55 \\
NPC/TSR\% & 101.74 & 100.07 & 60.85 & 166.92 & 101.87 \\
Ref [22] & & & & & \\
\hline
\end{tabular}

\section{CONCLUSIONS}

This paper presented the NPC method for maximum wind 
energy extraction of a variable-speed wind turbine. The proposed predictive method uses a nonlinear optimization problem which has been solved by an efficient search method to obtain an optimal torque (OT) control signals that takes advantage of the previewed averaged wind speeds. This method has several advantages compared with existing methods such as simpler controller design with low computational burden and the direct search of the optimal torque from the defined solution sets. Finally, it is clearly seen that the proposed $N P C$ method has a superior performance in wind energy extraction. On the other side, we have calculated the mean and STD values for power coefficient and generator torque, which is found that the results have confirmed the effectiveness and superiority of the proposed NPC method compared to the TSR method.

In summary, it should be noted here that the proposed NPC control method is a very promising and attractive method and has been proven to be highly efficient in wind energy extraction of a variable-speed wind turbine due to its intuitive concept and as well as its excellent tests results.

\section{ACKNOWLEDGMENT}

The author(s) received no financial support for the research, authorship, and/or publication of this paper. Furthermore, there is no conflict of interest exists.

\section{REFERENCES}

[1] Enevoldsen, P., Jacobson, M.Z. (2021). Data investigation of installed and output power densities of onshore and offshore wind turbines worldwide. Energy for Sustainable Development, 60: 40-51. https://doi.org/10.1016/j.esd.2020.11.004

[2] Sadorsky, P. (2021). Wind energy for sustainable development: Driving factors and future outlook. Journal of Cleaner Production, 289: 125779. https://doi.org/10.1016/j.jclepro.2020.125779

[3] Söder, L., Tómasson, E., Estanqueiro, A., Flynn, D., Hodge, B.M., Kiviluoma, J. (2020). Review of wind generation within adequacy calculations and capacity markets for different power systems. Renewable and Sustainable Energy Reviews, 119: 109540. https://doi.org/10.1016/j.rser.2019.109540

[4] Kasbi, A., Rahali, A. (2021). Performance improvement of modern variable-velocity wind turbines technology based on the doubly-fed induction generator (DFIG). Materials Today: Proceedings, 45: 5426-5432. https://doi.org/10.1016/j.matpr.2021.02.114

[5] Elsonbaty, N.A., Enany, M.A., Diab, A.M. (2018). Proposed control policy for high power transfer capability DFIG. Electric Power Systems Research, 155: 144-152. https://doi.org/10.1016/j.epsr.2017.10.012

[6] Chen, Z., Yin, M., Zou, Y., Meng, K., Dong, Z. (2016). Maximum wind energy extraction for variable speed wind turbines with slow dynamic behavior. IEEE Transactions on Power Systems, 32(4): 3321-3322. https://doi.org/10.1109/TPWRS.2016.2623981

[7] Prajapat, G.P., Senroy, N., Kar, I.N. (2021). Estimation based enhanced maximum energy extraction scheme for DFIG-wind turbine systems. Sustainable Energy, Grids and Networks, $\quad 26$ : 100419. https://doi.org/10.1016/j.segan.2020.100419

[8] Dekali, Z., Baghli, L., Boumediene, A. (2019). Indirect power control for a grid connected double fed induction generator based wind turbine emulator. In 2019 International Conference on Advanced Electrical Engineering (ICAEE), pp. 1-6. https://doi.org/10.1109/ICAEE47123.2019.9014778

[9] Yan, R., Saha, T.K. (2015). A new tool to estimate maximum wind power penetration level: In perspective of frequency response adequacy. Applied Energy, 154: 209-220. https://doi.org/10.1016/j.apenergy.2015.04.085

[10] Le, H.T., Santoso, S. (2013). Operating compressed-air energy storage as dynamic reactive compensator for stabilising wind farms under grid fault conditions. IET Renewable Power Generation, 7(6): 717-726. https://doi.org/10.1049/iet-rpg.2011.0247

[11] Qais, M., Hasanien, H.M., Alghuwainem, S. (2020). Salp swarm algorithm-based TS-FLCs for MPPT and fault ride-through capability enhancement of wind generators. ISA Transactions, 101: 211-224. https://doi.org/10.1016/j.isatra.2020.01.018

[12] Kazmi, S.M.R., Goto, H., Guo, H.J., Ichinokura, O. (2010). A novel algorithm for fast and efficient speedsensorless maximum power point tracking in wind energy conversion systems. IEEE Transactions on Industrial Electronics, 58(1): 29-36. https://doi.org/10.1109/TIE.2010.2044732

[13] Zhou, Q., Wang, C.G., Li, Z.X., Zhang, H., Zhang, N.Y., Yin, M.H. (2017). An improved MPPT control strategy based on adaptive optimization of speed reference. In 2017 Chinese Automation Congress (CAC), pp. 65726577. https://doi.org/10.1109/CAC.2017.8243961

[14] Yin, M., Li, W., Chung, C.Y., Zhou, L., Chen, Z., Zou, Y. (2017). Optimal torque control based on effective tracking range for maximum power point tracking of wind turbines under varying wind conditions. IET Renewable Power Generation, 11(4): 501-510. https://doi.org/10.1049/iet-rpg.2016.0635

[15] Nasiri, M., Milimonfared, J., Fathi, S.H. (2014). Modeling, analysis and comparison of TSR and OTC methods for MPPT and power smoothing in permanent magnet synchronous generator-based wind turbines. Energy Conversion and Management, 86: 892-900. https://doi.org/10.1016/j.enconman.2014.06.055

[16] Hand, M.M. (1999). Variable-speed wind turbine controller systematic design methodology: A comparison of non-linear and linear model-based designs (No. NREL/TP-500-25540). National Renewable Energy Lab., Golden, CO (US). https://doi.org/10.2172/12172

[17] Pan, L., Wang, X. (2020). Variable pitch control on direct-driven PMSG for offshore wind turbine using Repetitive-TS fuzzy PID control. Renewable Energy, 159: https://doi.org/10.1016/j.renene.2020.05.093

221-237.

[18] Habibi, H., Nohooji, H.R., Howard, I. (2018). Adaptive PID control of wind turbines for power regulation with unknown control direction and actuator faults. IEEE Access, 6: 37464-37479. https://doi.org/10.1109/ACCESS.2018.2853090

[19] Harrag, A., Messalti, S. (2015). Variable step size modified P\&O MPPT algorithm using GA-based hybrid offline/online PID controller. Renewable and Sustainable Energy Reviews, 49: 1247-1260. 
https://doi.org/10.1016/j.rser.2015.05.003

[20] Yaldiz, A., Kara, T. (2018). Optimal control of a wind turbine by using a linear matrix inequality (LMI) formulation. 2018 1st International Eurasian Conference on Science, Engineering and Technology (EurasianSciEnTech 2018), pp. 914-920.

[21] Salhi, S., Salhi, S. (2019). LQR control of a Grid Side Converter of a DFIG based WECS: LMI approach based on Lyapunov condition. In 2019 16th International Multi-Conference on Systems, Signals \& Devices (SSD), pp. 595-600. https://doi.org/10.1109/SSD.2019.8893266

[22] Song, D., Yang, Y., Zheng, S., Deng, X., Yang, J., Su, M. (2020). New perspectives on maximum wind energy extraction of variable-speed wind turbines using previewed wind speeds. Energy Conversion and Management, 206: 112496 https://doi.org/10.1016/j.enconman.2020.112496

[23] Song, D., Yang, J., Dong, M., Joo, Y.H. (2017). Model predictive control with finite control set for variablespeed wind turbines. Energy, 126: 564-572. https://doi.org/10.1016/j.energy.2017.02.149

[24] Song, D.R., Li, Q.A., Cai, Z., Li, L., Yang, J., Su, M., Joo, Y.H. (2018). Model predictive control using multi-step prediction model for electrical yaw system of horizontalaxis wind turbines. IEEE Transactions on Sustainable Energy, 10(4): 2084-2093. https://doi.org/10.1109/TSTE.2018.2878624

[25] Kitajima, T., Yasuno, T. (2015). Maximum power control system for small wind turbine using predicted wind speed. IEEJ Transactions on Electrical and Electronic Engineering, 10(1): 55-62. https://doi.org/10.1002/tee.22065

[26] Roig, M.G. (2017). Application of model predictive control to wind turbines. ETH Zürich.

[27] Manukonda, D., Gorantla, S.R. (2019). Simulation of model predictive controller based oscillatory water pumping system for residential applications. Journal Européen des Systèmes Automatisés, 52(6): 655-661. https://doi.org/10.18280/jesa.520614

[28] Benzouaoui, A., Khouidmi, H., Bessedik, B. (2021). Parallel model predictive direct power control of DFIG for wind energy conversion. International Journal of Electrical Power \& Energy Systems, 125: 106453. https://doi.org/10.1016/j.ijepes.2020.106453

[29] Zhou, Y., Shi, Y. (2016). Scenario-based stochastic model predictive control for wind energy conversion system. In 2016 Chinese Control and Decision Conference (CCDC), pp. 6222-6227. https://doi.org/10.1109/CCDC.2016.7532117

[30] Kumar, R., Agrawal, H.P., Shah, A., Bansal, H.O. (2019). Maximum power point tracking in wind energy conversion system using radial basis function based neural network control strategy. Sustainable Energy Technologies and Assessments, 36: 100533. https://doi.org/10.1016/j.seta.2019.100533

[31] Toriki, M.B., Asy'ari, M.K., Musyafa', A. (2021). Enhanced performance of PMSG in WECS using MPPT - fuzzy sliding mode control. Journal Européen des Systèmes Automatisés, 54(1): 85-96. https://doi.org/10.18280/jesa.540110

[32] Babu, P.S., Sundarabalan, C.K., Balasundar, C., Krishnan, T.S. (2021). Fuzzy logic based optimal tip speed ratio MPPT controller for grid connected WECS. Materials Today: Proceedings, 45: 2544-2550. https://doi.org/10.1016/j.matpr.2020.11.259

[33] Taibi, F., Benzineb, O., Tadjine, M., Boucherit, M.S., Benbouzid, M.E.H. (2014). Hybrid sliding mode control of DFIG with MPPT using three multicellular converters. IFAC Proceedings Volumes, 47(3): 11659-11666. 10.3182/20140824-6-ZA-1003.01592

[34] Dursun, E.H., Kulaksiz, A.A. (2020). Second-order sliding mode voltage-regulator for improving MPPT efficiency of PMSG-based WECS. International Journal of Electrical Power \& Energy Systems, 121: 106149. https://doi.org/10.1016/j.ijepes.2020.106149

[35] Yazici, İ., Yaylaci, E.K. (2017). Maximum power point tracking for the permanent magnet synchronous generator-based WECS by using the discrete-time integral sliding mode controller with a chattering-free reaching law. IET Power Electronics, 10(13): 1751-1758.

[36] Rezaei, M.M. (2018). A nonlinear maximum power point tracking technique for DFIG-based wind energy conversion systems. Engineering Science and Technology, an International Journal, 21(5): 901-908. https://doi.org/10.1016/j.jestch.2018.07.005

[37] Huang, C., Li, F., Jin, Z. (2015). Maximum power point tracking strategy for large-scale wind generation systems considering wind turbine dynamics. IEEE Transactions on Industrial Electronics, 62(4): 2530-2539. https://doi.org/10.1109/TIE.2015.2395384

[38] Kim, K.H., Van, T.L., Lee, D.C., Song, S.H., Kim, E.H. (2012). Maximum output power tracking control in variable-speed wind turbine systems considering rotor inertial power. IEEE Transactions on Industrial Electronics, $\quad 60(8)$ : 3207-3217. https://doi.org/10.1109/TIE.2012.2200210

[39] Zhao, Y., Wei, C., Zhang, Z., Qiao, W. (2013). A review on position/speed sensorless control for permanentmagnet synchronous machine-based wind energy conversion systems. IEEE Journal of Emerging and Selected Topics in Power Electronics, 1(4): 203-216. https://doi.org/10.1109/JESTPE.2013.2280572

[40] Prakash, A.O., Banu, R.N., Devaraj, D. (2019). Maximum energy extraction of a wind farm using pitch angle control. In 2019 IEEE International Conference on Intelligent Techniques in Control, Optimization and Signal Processing (INCOS), pp. 1-7. https://doi.org/10.1109/INCOS45849.2019.8951361

[41] Vighnesh, P.S., Joseph, S.R., Rajmohan, C., Chamundeeswari, V. (2018). Maximum power extraction in wind energy system with pitch angle control. In 2018 International Conference on Communication and Signal Processing (ICCSP), pp. 0590-0593. https://doi.org/10.1109/ICCSP.2018.8524305

[42] Mutoh, N., Nagasawa, A. (2006). A maximum power point tracking control method suitable for multi-parallelconnected compact wind power generators with selfpitch controlled blades. In IECON 2006-32nd Annual Conference on IEEE Industrial Electronics, pp. 42784284. https://doi.org/10.1109/IECON.2006.347811

[43] Azzouz, S., Messalti, S., Harrag, A. (1874). A Novel hybrid MPPT controller using (P\&O)-neural networks for variable speed wind turbine based on DFIG a novel hybrid MPPT controller using (P\&O)-neural Networks for Variable Speed Wind Turbine Based on DFIG, 92(1): 23-29. https://doi.org/10.18280/mmc_a.920104

[44] Ahmed, R., Namaane, A., M'Sirdi, N.K. (2013). Improvement in perturb and observe method using state 
flow approach. Energy Procedia, 42: 614-623. https://doi.org/10.1016/j.egypro.2013.11.063

[45] Mousa, H.H., Youssef, A.R., Mohamed, E.E. (2021). State of the art perturb and observe MPPT algorithms based wind energy conversion systems: A technology review. International Journal of Electrical Power \& Energy $\quad$ Systems, 126 : 106598. https://doi.org/10.1016/j.ijepes.2020.106598

[46] Buehring, I.K., Freris, L.L. (1981). Control policies for wind-energy conversion systems. In IEE Proceedings $\mathrm{C}$ (Generation, Transmission and Distribution), 128(5): 253-261. https://doi.org/10.1049/ip-c.1981.0043

[47] Benakcha, M., Benalia, L., Tourqui, D.E., Benakcha, A. (2018). Backstepping control of dual stator induction generator used in wind energy conversion system. International Journal of Renewable Energy Research, 8(1): 384-395.

[48] Poultangari, I., Shahnazi, R., Sheikhan, M. (2012). RBF neural network based PI pitch controller for a class of 5MW wind turbines using particle swarm optimization algorithm. ISA Transactions, 51(5): 641-648. https://doi.org/10.1016/j.isatra.2012.06.001

[49] Liu, H., Locment, F., Sechilariu, M. (2017). Experimental analysis of impact of maximum power point tracking methods on energy efficiency for smallscale wind energy conversion system. IET Renewable Power Generation, 11(2): 389-397. https://doi.org/10.1049/iet-rpg.2016.0083

[50] Abdullah, M.A., Yatim, A.H.M., Tan, C.W., Saidur, R. (2012). A review of maximum power point tracking algorithms for wind energy systems. Renewable and Sustainable Energy Reviews, 16(5): 3220-3227. https://doi.org/10.1016/j.rser.2012.02.016

[51] Moor, G.D., Beukes, H.J. (2004). Maximum power point trackers for wind turbines. In 2004 IEEE 35th Annual Power Electronics Specialists Conference (IEEE Cat. No. 04CH37551), 3: 2044-2049.

[52] Luo, X., Niu, S. (2016). A novel contra-rotating power split transmission system for wind power generation and its dual MPPT control strategy. IEEE Transactions on Power Electronics, 32(9): 6924-6935. https://doi.org/10.1109/TPEL.2016.2629021

[53] Zouggar, E.O., Chaouch, S., Abdelhamid, L., Abdeslam, D.O. (2021). Real-time implementation of the MPPT control algorithms of a wind energy conversion system by the digital simulator OPAL_RT. European Journal of Electrical Engineering, 23(1): 45-52. https://doi.org/10.18280/ejee.230106

[54] Wei, C., Zhang, Z., Qiao, W., Qu, L. (2015). Reinforcement-learning-based intelligent maximum power point tracking control for wind energy conversion systems. IEEE Transactions on Industrial Electronics, 62(10): 6360-6370.

\section{NOMENCLATURE}

\author{
Abbreviations \\ FAST fast aeroelastic simulation technologies \\ MWEE maximum wind energy extraction \\ MPPT maximum power point \\ MPC model predictive control \\ NMPC nonlinear model predictive control \\ NREL National Renewable Energy Laboratory \\ OT optimal torque \\ STD standard deviation \\ TSR tip speed ratio \\ VSWTs variable-speed wind turbines \\ WT wind turbine \\ WSR wind speed measurement
}

\section{Symbols}

$V_{v} \quad$ wind speed

$\Omega_{t} \quad$ rotor (turbine) speed

$\Omega_{t}^{*} \quad$ referential rotor (turbine) speed

$\Omega_{t}^{\min } \quad$ minimal rotor (turbine) speed

$\Omega_{t}^{\max } \quad$ maximal rotor (turbine) speed

$\Omega_{t}^{\text {nom }} \quad$ nominal rotor (turbine) speed

$\Omega_{g} \quad$ generator speed

$\Omega_{g}^{*} \quad$ referential generator speed

$P_{\text {aer }} \quad$ aerodynamic energy

$\lambda \quad$ vertical speed ratio

$\lambda_{\text {opt }} \quad$ optimum value of $\lambda$

$T_{t} \quad$ rotor (turbine) torque

$T_{g} \quad$ generator torque

$\boldsymbol{T}_{\boldsymbol{g}}^{*} \quad$ demanded generator torque.

$T_{g}^{\min } \quad$ minimum generator torque

$T_{g}^{\max } \quad$ maximum generator torque

$J_{t} \quad$ rotor (turbine) inertia

$J_{g} \quad$ generator inertia

$K_{f} \quad$ viscous friction coefficient

$R \quad$ rotor radius

$\beta \quad$ blades wedge angle

$\rho \quad$ air density

$C_{P} \quad$ aerodynamic power coefficient

$C_{p}^{\max } \quad$ maximum power coefficient

$G \quad$ gearbox ratio

$\tau_{g} \quad$ electrical time constant

$E \quad$ extracted wind energy

$E_{\text {max }} \quad$ maximum extracted wind energy

$T \quad$ long period

$n$ short period

$\Delta k \quad$ time length of short period $n$

$\mathrm{i} \quad \mathrm{i}^{\text {th }}$ control period

$\sigma_{1}, \sigma_{2} \quad$ two constants

$\mathrm{K}_{\Omega} \quad$ weighting factor 